\title{
O ALUNO COM ALTAS HABILIDADES/SUPERDOTAÇÃO EM ESCOLA RIBEIRINHA NA AMAZÔNIA
}

\author{
EL ESTUDIANTE CON ALTAS HABILIDADES / EXPERIENCIA EN LA ESCUELA \\ RIBEIRINHA EN AMAZONIA
}

\section{THE STUDENT WITH HIGH SKILLS/GIFTEDNESS IN RIVERSIDE SCHOOL IN AMAZON}

\author{
José Adnilton Oliveira FERREIRA ${ }^{1}$ \\ Relma Urel Carbone CARNEIRO ${ }^{2}$
}

RESUMO: Neste estudo investigou-se a inclusão de um aluno com altas habilidades/superdotação em escola ribeirinha na Amazônia Amapaense. Para tanto realizouse uma pesquisa baseada na abordagem qualitativa, a partir da seguinte questão de pesquisa: Como tem se dado a inclusão escolar de um aluno com altas habilidades/superdotação em uma escola ribeirinha no município de Mazagão no Estado do Amapá? A pesquisa teve como objetivo geral analisar o processo de inclusão de alunos com altas habilidades/superdotação do $1^{\circ}$ ao $5^{\circ}$ ano do Ensino Fundamental. O lócus da pesquisa foi uma Escola ribeirinha localizada no município de Mazagão no Estado do Amapá. Para a coleta dos dados foram realizadas entrevistas semiestruturadas, observação e registro fotográfico. Os participantes da referida pesquisa foram um professor da turma do aluno com altas habilidades/superdotação, um professor do Atendimento Educacional Especializado, um aluno com altas habilidades/ /superdotação, um coordenador pedagógico e o diretor da escola. Os dados coletados foram analisados a partir da análise de conteúdo, considerando a definição da categoria apriorística: inclusão escolar, assim como outras categorias intermediárias e categorias finais que no caso são as não apriorísticas que emergiram do referencial teórico adotado na pesquisa e da investigação empírica. Os resultados apontaram que existem dificuldades, no processo de inclusão deste público, relacionadas a vários aspectos como a formação de professores e de toda equipe escolar, de infraestrutura, de organização das salas de aula, entre outros, bem como, demonstraram a importância de pesquisas neste universo para o fortalecimento de questões teórico-práticas relativas à inclusão.

PALAVRAS-CHAVE: Inclusão escolar. Altas habilidades/superdotação. Amazônia amapaense. Educação ribeirinha.

RESUMEN: Este estudio investigó la inclusión de un estudiante con altas habilidades/regalidad en una escuela ribereña en la Amazonía de Amapa. Para ello, se llevó a cabo una investigación basada en el enfoque cualitativo, basado en la siguiente pregunta de investigación: ¿Cómo se ha dado la inclusión escolar de un estudiante con altas habilidades/regalidad en una escuela ribereña en el municipio de Mazago en el estado de

${ }^{1}$ Universidade de Brasília (UNB) Brasília - DF - Brasil. Doutorando em Educação pela Universidade de Brasília (UNB). ORCID: https://orcid.org/0000-0003-1732-3300. E-mail: joseadnilton_ap@yahoo.com.br.

${ }^{2}$ Universidade Estadual Paulista (Unesp), Araraquara - SP - Brasil. Pós-graduação em Educação Escolar. ORCID: https://orcid.org/0000-0002-8961-3617. E-mail: relma.urel@unesp.br

RPGE- Revista on line de Política e Gestão Educacional, Araraquara, v. 24, n. 1, p. 247-269, jan./abr., 2020. e-ISSN:1519-9029. 
Amapá? La investigación tuvo como objetivo general analizar el proceso de inclusión de estudiantes con altas habilidades / sobreasignación desde el lo hasta el 5 o año de la escuela primaria. El locus de la investigación fue una escuela ribereña ubicada en el municipio de Mazagón en el estado de Amapá. Se realizaron entrevistas semiestructuradas, observación y registro fotográfico para la recopilación de datos. Los participantes de esta investigación fueron un profesor de la clase del estudiante con altas habilidades / donación, un profesor de atención educativa especializada, un estudiante con altas habilidades // dote, un coordinador pedagógico y el director de la escuela. Los datos recogidos se analizaron a partir del análisis de contenido, considerando la definición de la categoría apriorista: inclusión escolar, así como otras categorías intermedias y categorías finales que en este caso son las sumas no aprioristas que surgieron del marco teórico adoptado en la investigación y la investigación empírica. Los resultados mostraron que existen dificultades en el proceso de inclusión de este público, relacionadas con diversos aspectos como la formación de los profesores y todo el equipo escolar, infraestructura, organización de aulas, entre otros, así como la importancia de la investigación en este universo para el fortalecimiento de cuestiones teórico-prácticas relacionadas con la inclusión.

PALABRAS CLAVE: Inclusión escolar. Altas habilidades / regalos. Amazon amapaense. Educación ribereña.

ABSTRACT: In this study we investigated the student with high skills/giftedness in a riverside School in Amapa's Amazon with possibility of inclusion in school? A research based on the qualitative approach was conducted, from the following problem question: How has the inclusion of a student with high skills/giftedness at a riverside school in the city of Mazagão in the state of Amapá been taking place? The study aimed to analyze the inclusion process of students with high skills/giftedness from the 1st to the 5th grade of elementary School. The locus of the research was a riverside school located in the municipality of Mazagão in the state of Amapá. For data collection, semi-structured interviews, observation and photographic recording were performed. The participants of this research were a teacher of the student's class with high skills/giftedness, a teacher of specialized educational attendance, a student with high skills/giftedness, a pedagogical coordinator and the school principal. The collected data was analyzed from the definition of the Aprioristic Category: school inclusion, as well as other intermediate categories and final categories that, in the case, are the non-aprioristic ones that emerged from the theoretical framework adopted in the research and Empirical research. As a result, this study brings significant theoretical and practical contributions to the process of inclusion of students with high skills/giftedness in this riverside School in the Amapa's Amazon. The results showed that there are difficulties in the process of inclusion of this public related to various aspects such as the formation of teachers and of the entire school team, infrastructure, the organization of classrooms, among others, as well as, demonstrate the importance of research in this universe to strengthen theoretical-practical questions related to inclusion.

KEYWORDS: School inclusion. High abilities/giftedness. Amapá's Amazon. Riverside education. 


\section{Introdução}

O contexto da investigação científica quanto à área de altas habilidades/superdotação (AH/S) infelizmente demonstra muita escassez na Educação do Brasil, embora os precursores da área tenham pesquisado e divulgado seus trabalhos a partir das décadas de 1920-1930.

Embora no exterior, no caso Europa e América do Norte, o tema Altas Habilidades/Superdotação (AH/S) já esteja sendo pesquisado desde os finais do século XIX, no Brasil, já se passaram mais de 80 anos desde sua primeira abordagem pelos pesquisadores e as investigações neste campo ainda são bastante escassas. Altas Habilidades/Superdotação é uma área recente de estudo, mas durante todo esse período de falta de investimentos na área, muitos talentos podem ter sido perdidos, desestimulados e encobertos. Tornam-se então pertinentes novas pesquisas como forma de contribuir para um correto atendimento a tais alunos (PEREZ, 2003).

É necessário pensar que, para desenvolver um trabalho pedagógico com os alunos visando prover as potencialidades, estimulando e orientando as habilidades, é preciso captar o que eles diferenciam como estimulante, ouvir atentamente o que eles expressam como interesse, inclinação e gosto, e encaminhar o ensino para esta direção, garantindo o envolvimento do aluno.

A opção por investigar a inclusão do aluno com altas habilidades/superdotação no processo educacional em uma escola do campo, dá-se pelos poucos estudos referentes à temática, assim como as condições de trabalho do professor, o acesso à escola pelos alunos e as especificidades regionais, econômicas, sociais e culturais que caracterizam as escolas do campo na Amazônia Amapaense.

A partir dessas indagações temos a seguinte questão de pesquisa: Como tem se dado a inclusão escolar de um aluno com altas habilidades/superdotação em uma escola ribeirinha da Amazônia Amapaense?

Para responder a ela definimos como objetivo geral: Analisar o processo de inclusão de um aluno com altas habilidades/superdotação em uma Escola ribeirinha no município de Mazagão no Estado do Amapá.

Por conseguinte temos como objetivos específicos: Conhecer a estrutura física e pedagógica da escola, assim como aspectos relacionados ao processo de ensino aprendizagem do aluno com altas habilidades/superdotação; Verificar as metodologias empregadas pelos professores no processo de ensino aprendizagem do aluno com altas habilidades/superdotação; Identificar as práticas de inclusão/exclusão do aluno com altas habilidades/superdotação 
realizadas na escola; e, Observar o aluno com altas habilidades/Superdotação nas suas interações sociais com os demais alunos em sala de aula.

Este estudo busca trazer contribuições teóricas e práticas significativas para entender/compreender se ocorre o processo de inclusão. As contribuições teóricas referem-se às descobertas feitas a partir da investigação da prática pedagógica do professor e da estrutura física e pedagógica da escola para atender os alunos com AH/S. No tocante às contribuições práticas, essas descobertas poderão subsidiar mudança na prática docente, bem como, sugerir melhorias na estrutura física e no projeto político pedagógico da escola e também contribuir, de maneira científica, com o meio acadêmico.

Nas Conclusões buscamos relacionar alguns pontos levantados durante toda a investigação, partindo do problema de pesquisa, as hipóteses e os objetivos, e buscando desenvolver algumas considerações e encaminhamentos para questão da inclusão do aluno com AH/S na escola pesquisada mediante as análises e discussões dos resultados da pesquisa.

\section{Da exclusão à inclusão}

A concepção de uma escola acolhedora para todos fundamenta-se, entre outros marcos, na Declaração Universal dos Direitos Humanos de 1948 (ONU, 2015) especificamente no seu artigo $26^{\circ}$ incisos I e II, que dispõe que todo ser humano tem direito à instrução, que a instrução será orientada no sentido do pleno desenvolvimento da personalidade humana e do fortalecimento do respeito pelos direitos humanos e pelas liberdades fundamentais. Nesse período amplia-se o crescimento de movimentos sociais que lutam por uma sociedade mais democrática, entre outros, fortalecendo as críticas ao modelo homogeneizador escolar e as práticas de segregação e categorização de estudantes vigente até então.

Por volta da década de 1970, uma proposta educacional denominada "Integração", protagonizou um movimento de integração social dos indivíduos que apresentavam deficiência, até então alijados do sistema de ensino, cujo objetivo era inseri-los em ambientes escolares. A partir de então, o conceito de normalização estende-se por toda a Europa e América do Norte. É no Canadá que se publica, em 1972, o primeiro livro acerca deste princípio, sendo seu autor Wolfensberger, que define este princípio como o uso dos meios normalizantes do ponto de vista cultural, para estabelecer e/ou manter comportamentos e características pessoais o mais normalizante possível, e o mais próximo daqueles oferecidos à pessoa sem deficiência. Porém, com uma concepção de normalidade que deveria ser buscada para que os alunos pudessem, aos poucos, participar do convívio social. "Tal proposta focava no sujeito com deficiência à 
necessidade de mudança e não se preocupava de forma efetiva com a mudança do ambiente para lidar com as diferenças" (SASSAKI, 1997).

A inclusão, em educação, traz consigo um objetivo, que é aceitar a diferença na escola e possibilitar a todos os estudantes o acesso ao conhecimento. A escola inclusiva parte de princípios distintos da proposta da integração, que foi caracterizada no final do século XX, para estimular a aceitação da sociedade, posta em prática nas escolas regulares que somente recebiam o aluno, sem a preocupação em realizar modificações na estrutura do sistema como um todo.

Dessa forma, cresce o interesse por uma escola inclusiva, que atenda a todos de maneira equânime.

Esse princípio foi documentado pela primeira vez em 1979 no México, porém, o movimento pela inclusão que representou um grande avanço na Educação Especial, iniciou-se nos Estados Unidos em 1981 na Assembleia Geral das Nações Unidas, que culminou com a criação de setores específicos para cuidar dessas questões nos ministérios públicos de vários países, na qual foi estabelecido o ano internacional das pessoas portadoras de deficiências (CHICON, 1999. s/p).

A partir deste marco, a inclusão escolar deve buscar verdadeiramente uma educação de qualidade para todos e tem como objetivo maior reconhecer, acolher e respeitar as diferenças no ambiente escolar e possibilitar o acesso, a permanência e a aprendizagem de todos os alunos na escola, sendo necessário o rompimento com o pressuposto da integração, que preconizava o direito da pessoa com deficiência ao espaço comum da vida em sociedade, mas este não previa a mudança no ambiente escolar efetivamente para o trabalho com as diferenças.

Contrapondo-se ao paradigma da integração, a inclusão escolar manifesta-se em uma estrutura que deve considerar os pressupostos do que é a valorização, participação e aceitação de pessoas que possuem necessidades específicas, considerando-as em suas diferenças, suas características individuais e os seus reais interesses, reconhecendo-os como parte do grupo, respeitando suas diferenças e colaborando de maneira positiva para a superação de seus desafios. Ao contrário da integração, a inclusão escolar tem em vista a participação de todos os alunos numa estrutura que considera as características, os interesses e os direitos de cada um.

A Constituição Federal de 1988 (BRASIL, 1988), por meio do artigo 205, garante o direito à educação a todos os indivíduos. Quando a constituição se refere ao termo "todos os indivíduos", subtende-se que não há distinção. No artigo 206 é ressaltada a igualdade de condições para acesso e permanência na escola. Observa-se então que, a Constituição garante a todos o direito objetivo de educação sem distinção de raça, sexo, cor, origem ou deficiência. 
Reforçando a ideia de inclusão em uma educação escolar para todos, podemos citar a importância da Declaração Mundial de Educação para Todos, elaborada em Jomtien (BRASIL, 1990) na Tailândia, a qual evidencia promover as transformações do sistema educacional, com intuito de assegurar o acesso e permanência de todos na escola, para que se possam sanar os altos índices de crianças, adolescentes e jovens sem escolarização.

De acordo com Werneck (2000) o conceito de educação inclusiva surge em 1994 na Conferência Mundial de Necessidades Educativas Especiais: Acesso e Qualidade, resultando na Declaração de Salamanca (UNESCO, 1994, p. 10): “com o objetivo de fornecer diretrizes básicas para a formulação e reforma de políticas e sistemas educacionais de acordo com o movimento de inclusão social”. Esta declaração é considerada um dos principais documentos que visam à inclusão social.

No entanto, para que tal processo se efetive é preciso que sejam identificadas as demandas que o aluno apresenta em sua interação no ambiente escolar, e proporcionar-lhe as condições necessárias para sua aprendizagem. A Declaração de Salamanca (UNESCO, 1994, p. 10) deixa claro esse aspecto quando afirma que "todas as crianças [...] têm direito fundamental à educação e que a elas deve ser dada a oportunidade de obter e manter um nível aceitável de conhecimentos".

Na Declaração de Salamanca ficou estabelecido que:

Toda criança tem direito fundamental à educação, e deve ser dada a oportunidade de atingir e manter o nível adequado de aprendizagem e toda criança possui características, interesses, habilidades e necessidades de aprendizagens que são únicas. Qualquer pessoa portadora de deficiência tem o direito de expressar seus desejos com relação à sua educação, tanto quanto estes possam ser realizados. Pais possuem o direito inerente de serem consultados sobre a forma de educação mais apropriada às necessidades, circunstâncias e aspirações de suas crianças (BRASIL, 2006. p. 33).

O princípio básico da Declaração de Salamanca é que a escola comum é um espaço determinante para o combate à exclusão e a discriminação, visando romper com as barreiras programáticas, possibilitando a efetivação das atitudes inclusivas, proporcionando a equiparação de oportunidades dentro do contexto escolar.

Embora a ideia de uma escola para todos, sem nenhuma forma de discriminação, por princípio deva considerar as características individuais dos alunos e, portanto, promover respostas para contemplá-las, a Lei de Diretrizes e Bases da Educação Nacional nº 9.394/96 (BRASIL, 1996) preconiza que a população considerada da Educação Especial e que, portanto, tem acesso ao atendimento educacional especializado, definindo em seu Artigo 58, "a educação especial como modalidade de educação escolar, oferecida preferencialmente na rede regular de 
ensino, para os educandos com deficiência, transtornos globais do desenvolvimento e altas habilidades ou superdotação". Continuando em seu artigo 59, que os sistemas de ensino devem assegurar aos alunos currículo, métodos, recursos e organização para atender as suas necessidades, assegura também a terminalidade específica àqueles que não atingiram o nível exigido para a conclusão do ensino fundamental, em virtude das deficiências; e assegura a aceleração dos superdotados para conclusão do programa escolar. Define também, dentre as normas para a organização da educação básica, no artigo 24 inciso V, a "possibilidade de avanço nos cursos e nas séries mediante a verificação do aprendizado" e "[...] oportunidades educacionais apropriadas, consideradas as características do alunado, seus interesses, condições de vida e trabalho, mediante cursos e exames" (art. 37).

A Política Nacional de Educação Especial na Perspectiva da Educação Inclusiva (BRASIL, 2008) conceitua a Educação Especial como modalidade transversal aos níveis, etapas e outras modalidades de ensino, além de estabelecer como público alvo da Educação Especial (PAEE) alunos com deficiências, transtornos globais do desenvolvimento e altas habilidades/superdotação. Tal política disponibiliza o atendimento educacional especializado AEE e os recursos próprios desse atendimento, orientando os alunos e professores quanto à utilização dos mesmos nas turmas comuns do ensino regular.

A Resolução CNE/CEB, n 4 (BRASIL, 2009), no seu artigo 4º, considera público-alvo do AEE:

I - Alunos com deficiência: aqueles que têm impedimentos de longo prazo de natureza física, intelectual, mental ou sensorial.

II - Alunos com transtornos globais do desenvolvimento: aqueles que apresentam um quadro de alterações no desenvolvimento neuropsicomotor, comprometimento nas relações sociais, na comunicação ou estereotipias motoras. Incluem-se nessa definição alunos com autismo clássico, síndrome de Asperger, síndrome de Rett, transtorno desintegrativo da infância (psicoses) e transtornos invasivos sem outra especificação.

III - Alunos com altas habilidades/superdotação: aqueles que apresentam um potencial elevado e grande envolvimento com as áreas do conhecimento humano, isoladas ou combinadas: intelectual, liderança, psicomotora, artes e criatividade.

Para outras características de diferenças que também requerem ações específicas da escola, a resolução acima citada prevê que a Educação Especial deve atuar na escola para possibilitar as respostas necessárias, que não se limite o processo inclusivo apenas aos alunos público alvo educação especial mas, principalmente, a todos os sujeitos que foram e ainda são historicamente excluídos e que vivem na invisibilidade dentro de uma sociedade excludente. 
Outro documento histórico, relevante, que reforça a ideia de uma escola para todos é a Declaração de Incheon, (UNESCO, 2015) elaborada na Correia do Sul/2015, que chama a atenção dos países para assegurar a educação inclusiva e equitativa da qualidade educacional, dessa forma promover oportunidades de aprendizagem ao longo da vida para todos. Com essa visão, transformadora e universal de educação, buscam abordar os desafios globais da educação. A citada Declaração é inspirada por uma visão humanista da educação, com base nos direitos humanos e na dignidade, na justiça social, na inclusão, na proteção, na diversidade cultural, linguística e étnica, na responsabilidade e na prestação de contas compartilhadas, e reafirma que a educação é um bem público, um direito humano fundamental e a base que garante a efetivação de outros direitos.

A Declaração de Incheon (2015) coloca o que é essencial para a paz, a tolerância, a realização humana e o desenvolvimento sustentável. Reconhece a educação como elementochave para se atingir o pleno emprego e a erradicação da pobreza e, reafirma a necessidade de concentrar nossos esforços no acesso, na equidade e na inclusão, bem como na qualidade e nos resultados da aprendizagem e no contexto de uma abordagem de educação ao longo da vida.

Partindo desta breve reflexão e da seguinte afirmação de Carmo (2000, p. 18) "a inclusão é um assunto que deve ser refletido e investigado com muita precisão, já que a sociedade pode estar criando uma nova modalidade: a de excluídos dentro da inclusão", é preciso que se reorganize a escola para que haja o processo de ensino-aprendizagem no que tange à inclusão escolar dos alunos da Educação Especial de forma realmente efetiva.

\section{Educação ribeirinha: desafios e perspectivas frente à Inclusão}

Segundo Molina e Freitas (2011) "Educação do Campo originou-se no processo de luta dos movimentos sociais camponeses que lutam pela construção de uma sociedade sem desigualdades e com justiça social”. A Educação Ribeirinha está inserida como uma das modalidades da Educação do Campo, em que essa luta por educação faz parte de suas estratégias de resistência que objetivam manter seus territórios de vida, trabalho e identidade e surgiu como reação ao histórico conjunto de ações educacionais que mantiveram precário o quadro de escolarização no campo e também contribuíram para aprofundar as desigualdades sociais no território campesino.

A Educação Ribeirinha é um assunto que, nas últimas décadas, tem granjeado relevante importância como uma forma de garantir o direito à educação da população ribeirinha. Esta modalidade educacional é oriunda dos movimentos sociais de homens e mulheres que 
consideram sua realidade social, econômica e política. Ou seja, ao discutir as mazelas da população ribeirinha, inevitavelmente aborda-se a questão da Educação do Campo, nesse movimento as lutas sociais por uma educação de qualidade devem ser consideradas.

O conceito de Educação do Campo, que engloba a Ribeirinha, é algo relativamente novo, mas está em evidência, exatamente porque a corrente ideológica que ele busca é marcada por contradições sociais bastante fortes. Caldart (2010) explica que a Educação do Campo surgiu em certo momento e seu contexto histórico configura-se como sendo um movimento de combate ao descaso imposto ao povo do campo (ausência de políticas para a educação e de projetos de melhoria para a vida no campo) e a Educação Ribeirinha faz parte desse esforço.

A educação ribeirinha tem várias peculiaridades, como o transporte pelo rio no casco, nome pelo qual a canoa é chamada, pois, é feita de madeira, não é qualquer madeira que dá para fazer o casco, tem que ser uma resistente à água e que não seja muito pesada.

Para entender a vida de um povo ribeirinho, primeiro é preciso saber que o Rio tem papel vital na organização social, cultural, religiosa e econômica dos mesmos. Os rios são as ruas, estradas, rodovias por onde se navega para ir à escola, à cidade e a outros lugares; do rio se retira o peixe, o camarão, a lagosta, a água para beber, fazer comida, higiene pessoal e da casa (ALMEIDA, 2016). Neste estudo, fizemos uma abordagem histórica referente à constituição da população que vive às margens dos rios na Amazônia para, posteriormente, situar a população amazônica.

O povo brasileiro, de acordo com Ribeiro (2006), é resultado do encontro do colonizador com os índios e negros africanos, que deram origem a um povo mestiço, com traços culturais distintos de suas matrizes formadoras.

A sociedade e a cultura brasileira são conformadas como variantes da versão lusitana da tradição civilizatória europeia ocidental, diferenciadas por coloridos herdados dos índios americanos e dos negros africanos. O Brasil emerge, assim, como um renovo mutante, remarcado de características próprias, mas atado geneticamente à matriz portuguesa, cujas potencialidades insuspeitadas de ser e de crescer só aqui se realizariam plenamente (RIBEIRO, 2006, p. 18).

O brasileiro é marcado por características próprias, como afirma o autor, é um povo em que a diversidade é o aspecto fundamental; para isso, a imigração, principalmente europeia, árabe e japonesa, bem como os vieses ecológico e econômico contribuiu significativamente. $\mathrm{O}$ ecológico gerou paisagens humanas distintas nas quais as condições ambientais obrigaram a adaptações, como é o caso do sertão nordestino e da Amazônia, por exemplo. 
Segundo Bezerra Neto (2013, p. 34), a apropriação pelos portugueses desta região envolveu as diversas etnias indígenas, por meio de variadas estratégias de dominação, assim como os colonizadores europeus e os escravos oriundos da África. Para o autor, "a mestiçagem envolvia diversos segmentos sociais e étnicos da Colônia. A constituição de mocambos formados por índios, africanos, colonos brancos e mestiços de todos os tons constituiu-se exemplo desta realidade".

Sobre este assunto afirma Rodrigues (2004, p. 23): “O biótipo característico do ribeirinho amazônida e seu modo de vida [...] são frutos da mescla de indivíduos de etnias e culturas diferentes, que conformaram o processo histórico de formação territorial e populacional”. Já Ribeiro (2006), ao abordar o processo de ocupação e constituição das populações da Amazônia, conclui que a formação cultural deste povo está fundada nas mesmas matrizes básicas citadas anteriormente pela migração oriunda do Nordeste ao final do século XIX e no período de 1943 a 1945, motivada pela batalha da borracha.

As migrações nordestinas para a Amazônia sempre estiveram ligadas às questões de conflitos no campo, coincidindo com os períodos de seca, e os pequenos agricultores são os que primeiro sentem os efeitos da mesma. Além de ser a maioria da população rural sertaneja, ela não tinha alternativa a não ser migrar (SILVA, 2000, p. 48).

As classes multisseriadas espelham a diversidade e a heterogeneidade da população campesina, atendendo crianças e jovens, com níveis de aprendizagem diferenciados, em séries distintas em um único espaço. Tal fato demonstra a importância de se identificar os saberes e as práticas dos docentes desta modalidade de ensino, visando superar as situações adversas encontradas no processo de ensino, que decorrem das condições de trabalho docente e formação.

É comum encontrar os professores lecionando em turmas do $1^{\circ}$ ao $5^{\circ}$ ano, até mesmo conjuntamente com alunos da Educação Infantil. "As classes multisseriadas são espaços marcados predominantemente pela heterogeneidade, ao reunirem grupos com diferenças de sexo, de idade, de interesses, de domínio de conhecimentos, de níveis de aproveitamento etc." (HAGE, 2005, p. 6).

Os acanhados programas, criados no Brasil, voltados para a Educação do Campo foram elaborados sem a participação de seu objeto direto, a população do campo (pequenos agricultores, quilombolas, indígenas, pescadores, camponeses, assentados e reassentados, ribeirinhos, povos de florestas, caipiras, lavradores, roceiros), sem que tivesse sua participação de forma direta e decisiva, mas, prontos e acabados para eles. 


\section{Alunos com altas habilidades/superdotação: conceituação}

O termo altas habilidades/superdotação faz referência a uma pessoa que possui habilidade significativamente acima da média. Segundo estimativa da Organização Mundial de Saúde (OMS/2014) existem de 3,5 a 5\% de pessoas com AH/S no conjunto da população universal.

Definem-se altas habilidades/superdotação pela seguinte argumentação: [...], os termos "pessoas com altas habilidades" e "superdotação" são mais apropriados para designar aquela criança ou adolescente que demonstra sinais ou indicações de habilidade superior em alguma área do conhecimento, quando comparada aos seus pares (BRASIL, 2007, p. 27).

É importante descrever sobre a conceituação adotada para essa pesquisa, preconizada nos dispositivos legais que utilizam terminologias que variam, tais como: altas habilidades ou superdotação por estar em consonância com a Lei de Diretrizes e Bases da Educação Nacional $\mathrm{N}^{\circ} 9394$ (BRASIL, 1996), que foi alterada pela Lei n 12.796 , em 4 de abril de 2013 (BRASIL, 2013a).

A nomenclatura utilizada na legislação, e que aparece em muitas publicações, é altas habilidades/superdotação (AH/S), que será adotada frequentemente nesse estudo, por estar de acordo com a Política Nacional da Educação Especial na Perspectiva da Educação Inclusiva (BRASIL, 2008).

\section{Método}

Diante deste contexto realizou-se a pesquisa partindo da seguinte questão problema: Como tem se dado a inclusão escolar do aluno com AH/S em uma escola ribeirinha da Amazônia Amapaense?

O lócus da pesquisa foi uma escola ribeirinha ${ }^{3}$ pertencente ao sistema de ensino do município de Mazagão no Estado do Amapá.

O problema e os objetivos propostos para a pesquisa levaram-nos a desenvolver uma pesquisa de campo que se norteia por uma abordagem qualitativa. Dentre os tipos de pesquisa qualitativa, optou-se pelo Estudo de Caso, por compreender que atende aos objetivos definidos neste estudo, que visam saber como se efetiva, de fato, a inclusão escolar de alunos com AH/S no $3^{\circ}$ ano do ensino fundamental I em uma escola ribeirinha no município de Mazagão no

${ }^{3}$ Escolas situadas às margens de rios, lagos ou igarapés.

RPGE- Revista on line de Política e Gestão Educacional, Araraquara, v. 24, n. 1, p. 247-269, jan./abr., 2020. e-ISSN:1519-9029. 
Estado do Amapá.

A pesquisa qualitativa propicia o contato direto do pesquisador com o ambiente pesquisado. Na visão de Ludke e André (1986), “o estudo de caso é sempre bem delimitado, devendo ter seus contornos claramente definidos no desenrolar do estudo". [...] O interesse incide naquilo que ele tem de único, de particular, mesmo que, posteriormente, venham a ficar evidentes certas semelhanças com outros casos ou situações. O estudo de caso qualitativo possui, segundo André (2003, p. 18) as seguintes características: “desenvolve-se numa situação natural, é rico em dados descritivos, tem um plano aberto e flexível e focaliza a realidade de forma complexa e contextualizada". Este tipo de pesquisa necessita de uma imersão no contexto.

A pesquisa qualitativa na abordagem do estudo de caso necessitou do contato direto por um período de tempo considerável para que se pudesse ter a vivência com o ambiente investigado. Nesse período o investigador aplicou técnicas necessárias para a produção de dados, considerando que Bogdan e Biklen (1994, p. 48) afirmam que investigadores qualitativos "frequentam os locais de estudo porque se preocupam com o contexto. Entendem que as ações podem ser observadas no seu ambiente natural de ocorrência".

\section{Procedimentos éticos}

A pesquisa foi submetida à avaliação pelo Comitê de Ética da UNESP, via Plataforma Brasil, tendo sido aprovada. Todos os participantes assinaram o termo de consentimento livre esclarecido em que constam todas as informações relacionadas à pesquisa e firmam o compromisso o ético do estudo.

\section{Participantes}

Os participantes da pesquisa foram um professor da turma em que estudava o aluno com $\mathrm{AH} / \mathrm{S}$, o aluno com AH/S, o professor do AEE, o coordenador pedagógico e o diretor da escola.

No quadro a seguir são apresentadas as características dos participantes da pesquisa. 
Quadro 01 - Caracterização dos participantes da pesquisa

\begin{tabular}{|c|c|c|c|c|}
\hline Participantes & $\begin{array}{c}\text { Tempo } \\
\text { Magistério }\end{array}$ & $\begin{array}{c}\text { Experiência com } \\
\text { Classes } \\
\text { Multisseriadas }\end{array}$ & $\begin{array}{c}\text { Formação } \\
\text { Educação Superior }\end{array}$ & Especialização \\
\hline Diretor 01 & 02 anos & 02 anos & Pedagogia & Ensino religioso \\
\hline Coordenador 01 & 01 ano & 01 ano & Pedagogia & Gestão Escolar \\
\hline $\begin{array}{c}\text { Professor C } \\
\text { (sala comum) }\end{array}$ & 02 anos & 02 anos & Pedagogia & $\begin{array}{c}\text { Metodologia da Língua } \\
\text { Portuguesa }\end{array}$ \\
\hline Professor AEE & 06 anos & 06 anos & Pedagogia & Não tem* \\
\hline Aluno & Idade/ Sexo & Série/ano & $\begin{array}{c}\text { Área/ Identificação } \\
\text { de AH/S }\end{array}$ & $\begin{array}{c}\text { Aluno } \\
\text { alteresse do }\end{array}$ \\
\hline Pedro (nome fictício) $* *$ & $\begin{array}{c}08 \text { anos/ } \\
\text { Masculino }\end{array}$ & $3^{\text {o Ano do E. F. }}$ & Lógica-matemática & Robótica \\
\hline
\end{tabular}

*O professor do AEE não possui especialização na área da Educação Especial que é comum nas escolas ribeirinhas da Amazônia em virtude da falta de profissionais.

**O referido aluno foi avaliado e identificado em março de 2016 pelo Centro de Atividades de Alunos com AH/S em Macapá - AP, mas não consta no Censo Escolar/INEP da referida escola pesquisada (BRASIL, 2016).

Fonte: Arquivo da Pesquisa/Dados coletados nas entrevistas.

\section{Instrumentos de coleta de dados}

Pesquisas qualitativas, conforme Alves-Mazzotti (2002, p. 163) "são multimetodológicas, isto é, usam uma grande variedade de procedimentos e instrumentos para coleta de dados". Assim sendo, para a produção dos dados foram realizadas entrevistas semiestruturadas, a observação in loco da prática pedagógica do professor da sala de aula regular e do AEE e a fotografia.

Além da aplicação dos roteiros de entrevistas, fizemos a observação por meio dos roteiros da prática pedagógica no cotidiano da sala de aula e do atendimento educacional especializado da escola, com registro de diário de campo.

Alves-Mazzotti (2002, p. 164) elenca as vantagens atribuídas à observação enquanto técnica para produção de dados:

[...] a) permite checar na prática a sinceridade de certas respostas que, às vezes, são dadas só para causar boa impressão; b) permite identificar comportamentos não intencionais ou inconscientes e explorar tópicos que os informantes não se sentem à vontade para discutir; c) permite o registro do comportamento em seu contexto temporal-espacial.

Utilizou-se o registro fotográfico do contexto no qual se desenvolve a prática pedagógica dos professores do aluno com $\mathrm{AH} / \mathrm{S}$. A fotografia produz um tipo de imagem que 
serve muito bem como mediadora da realidade: uma forma de capturar os objetos e tornar desnecessária a sua presença. Por ela, é possível conhecer lugares ou pessoas sem sair do lugar.

Wolff (2005) corrobora que existe certa maleabilidade entre os limites do objeto e seu retrato e, embora tomemos a fotografia como o próprio objeto, é preciso que exista também a diferenciação do que é fotografia e o que é realidade: estas não devem se assemelhar tanto para que a fotografia represente algo, seja uma referência ou uma alusão ao objeto. Em outras palavras, tomamos a fotografia como o objeto real, mas sabemos que não o é.

Em relação aos professores e a escola investigada, realizamos a observação analítica da prática pedagógica com dois (02) professores da pesquisa, no caso um da sala de aula regular, e outro do atendimento educacional especializado (AEE) e com aluno AH/S.

As observações foram realizadas a partir do início do mês de setembro, prosseguindo em outubro e novembro de 2016, reiniciando em fevereiro, março, abril até o final do mês de maio de 2017, com uma média de um encontro de observação por mês com duração de 03 (três horas) diárias na sala de aula do professor regular, verificação e investigação da estrutura física, administrativa e pedagógica e do professor do AEE, totalizando 07 encontros em um período de 07 meses de pesquisa na escola campo.

Para preservar o anonimato dos cinco participantes, optamos por identificá-los como: Diretor 01; Coordenador 01; Professor Sala de aula Comum; Professor AEE; Aluno: nome fictício de Pedro.

\section{Apresentação, análise e discussão dos resultados}

A partir dos dados definimos as categorias não apriorísticas: Formação continuada sobre altas habilidades/superdotação; Acesso à escola, estrutura física, administrativa e pedagógica da escola; Prática pedagógica em classes multisseriadas e interação social. Procurou-se estabelecer um diálogo entre essas categorias finais e o referencial teórico. Trabalhou-se com as falas dos sujeitos, no sentido de dar visibilidade aos seus discursos, suas teorias, suas práticas, seus valores e costumes que emergiram ao longo da pesquisa de campo.

\section{Formação continuada sobre AH/S}

A seguir damos visibilidade à primeira categoria não apriorística, que é sobre a "Formação continuada dos profissionais" que atuam na escola ribeirinha pesquisada, considerando que a mesma deve ser pensada de forma macro, não somente pelo professor de 
sala de aula comum ou do atendimento educacional especializado, mas, necessariamente, por todos profissionais da educação.

Nesse caso, pensando em formação para os professores que atuam ou atuarão na Educação Especial, parece-nos que os professores se formam sem a devida preparação para o atendimento aos alunos com $\mathrm{AH} / \mathrm{S}$ que estão nas escolas.

Observa-se a fragilidade da formação inicial e a escassez da formação em serviço para esses profissionais quanto a $\mathrm{AH} / \mathrm{S}$, que os habilite para o exercício da docência e a necessidade da obtenção de formação específica para a Educação Especial. Quanto à oferta de cursos de especialização voltada à área de AH/S, Delou (2012, p. 341) explicita que:

Considerando-se a recém oferta de cursos de formação de professores a distância na área da Educação Especial, resolve-se, aparentemente, o problema do acesso de um número cada vez maior de professores interessados na área em contrapartida ao pequeno número de professores disponíveis nas universidades públicas e privadas para a constituição de um grupo docente responsável pela formação presencial. Contudo, ainda vemos cursos sendo autorizados e oferecidos sem a oferta da área das altas habilidades/superdotação.

Entende-se que a formação continuada dos profissionais sobre AH/S, engloba um espectro amplo de conhecimentos e habilidades frente ao processo de inclusão escolar desses alunos. Os programas de capacitação devem reconhecer a importância da subjetividade e da identificação desses sujeitos, isso implica, necessariamente, reconhecer um amplo contexto de habilidades humanas, em consequência, definir propostas de atendimento, por meio de programas de enriquecimento curricular, cujos processos de seleção não sejam restritos somente a testes objetivos.

\section{Acesso à escola, estrutura física, administrativa e pedagógica}

A segunda categoria final, descrita como categoria não apriorística, "O Acesso à escola, estrutura física, administrativa e pedagógica" e de que forma se mostra como um implicador no processo de inclusão escolar dos alunos com AH/S em escolas ribeirinhas da Amazônia.

Cabe aqui retratar algumas informações contidas no roteiro de observação da estrutura física da escola investigada, para dialogar com as falas dos sujeitos da pesquisa e reiterar as dificuldades encontradas no contexto da pesquisa. Como forma de conhecer a instituição observou-se o espaço físico da escola e do seu entorno. Esta parte refere-se à estrutura e organização física da instituição. Observação da parte externa do prédio, sua fachada e adjacências. 
A estrutura do prédio é muito antiga, em sua maior parte de madeira, a escola é limpa e arejada, mas é visível a precariedade da estrutura física que está gasta pelo tempo, tem adaptações, necessitando urgentemente de uma reforma no prédio que não tem climatização e sua instalação elétrica e hidráulica é improvisada. A fachada é antiga, tem uma rampa que desce para o rio, onde os barcos ancoram. A escola localiza-se em área ribeirinha um pouco longe do centro comercial de Mazagão. Descrevendo a parte interna, as portas e janelas são bem antigas, com venezianas, seu terreno é pequeno e não possui quadra poliesportiva (Roteiro de observação da estrutura física).

As dificuldades da realidade das escolas ribeirinhas na Amazônia são inúmeras, primeiramente por serem geograficamente isoladas, uma longe da outra e o acesso para essas escolas nas comunidades ribeirinhas de Mazagão é praticamente quase todo pelo rio. No caso da escola pesquisada só se consegue acesso através desse porto, o que é extremamente difícil por se tratar de região Amazônica, onde a mobilidade das pessoas da zona urbana, e até mesmo dos ribeirinhos nos igarapés, rios e mata, torna-se fator dificultador.

\section{Prática pedagógica em classes multisseriadas e interação social}

Em continuidade à análise apresentou-se a categoria final: "Prática pedagógica em classes multisseriadas e interação social", em que está explicitada a forma como os ribeirinhos atuam, transformam e criam uma realidade que também os transforma e direciona suas maneiras de agir e pensar, pois, ao transformar o ambiente na sua interação social, sofrem os efeitos de sua própria transformação.

Ainda referente à sua prática pedagógica para o $\mathrm{AEE}$ com $\mathrm{AH} / \mathrm{S}$, perguntou-se para o professor do AEE sobre: Ambiente do AEE e da sala de aula comum e a demanda de atividades de ensino, experiências exploratórias, e conseguiu-se a seguinte resposta:

Ambiente AEE e sala comum: Bem o caso do PEDRO, mostra-se produtivo na sala, ele tem uma grande facilidade em Matemática, mas dificuldade em outras áreas, mas ele já avançou bastante, mas devemos sensibilizar a professora do ensino regular que é uma guerreira, já que trabalha com classes multisseriadas com crianças com tantas diferenças de idade e de escolaridade, então é um grande desafio ainda ter um altas habilidades em sala, ainda com toda essa precarização da escola, entendo que tenhamos comprometimento profissional, mas devemos cobrar mais estrutura e recursos para desenvolver o processo de ensino aprendizagem como um todo (Professor AEE).

Demanda das atividades de ensino: Claro que devemos trabalhar o conhecimento que o aluno tem, no caso do PEDRO utilizamos as fichas de atividades e o trabalho com o professor da sala de aula regular onde trabalhamos com o enriquecimento curricular (Professor AEE). 
De acordo com as respostas do Professor AEE nas interrogações sobre Avaliação, ambiente AEE e sala comum e as demandas de ensino no caso do aluno PEDRO, percebe-se a importante participação do Centro de Atividades de Altas Habilidades/Superdotação no diagnóstico e o apoio aos profissionais da escola pesquisada, já que esses professores não dispõem dos recursos e dos materiais para o referido atendimento ao aluno com AH/S, além de a precariedade da realidade da classe multisseriada da escola do campo ser um impeditivo para que se realize um trabalho pedagógico de qualidade com essas crianças da Educação Especial, principalmente na prática com o aluno Pedro.

A partir desta análise, no que tange à prática pedagógica, o Diretor 01, quando perguntado: Em sua opinião enquanto gestor(a) pensando na formação profissional do professor(a) em sala de aula comum diante da perspectiva da inclusão escolar dos alunos com $\mathrm{AH} / \mathrm{S}$, quais são os principais desafios? Respondeu da seguinte forma:

Pensando que o professor tem um papel preponderante na aprendizagem, esse profissional deve ter o perfil, principalmente, para trabalhar na escola de campo em salas multisseriadas que é um grande desafio, creio que para trabalhar com aluno com altas habilidades deve demonstrar dinamicidade $e$ vontade de aprender sempre, para suscitar o desejo de aprender do aluno. Dessa forma esse professor da sala de aula comum deve mostrar, principalmente, essa vontade de incluir o aluno superdotado, acho que devemos acreditar na inclusão na sala de aula, aqui todos mostram respeito uns pelos outros, porém eu penso para desenvolver para área da habilidade e competência da superdotação, precisaríamos de incentivo e apoio maior da secretária de Educação (Diretor 01).

Observa-se a preocupação com a identificação e potencialização dos alunos com AH/S por parte do gestor da escola, mas infelizmente as adversidades da realidade (acesso à escola, currículo inadequado/homogêneo) e a falta de políticas educacionais, acarretada principalmente pela discriminação com escolas ribeirinhas na Amazônia, são fatores que impedem uma prática pedagógica que favoreça os alunos com AH/S e que eles sejam realmente percebidos.

Entendendo que qualquer prática pedagógica deve ter o ambiente de aprendizagem propício (estrutura física, material pedagógico e didático) para que o processo de aprendizagem ocorra de forma produtiva e com qualidade, que não é o caso da realidade investigada, não somente dessa escola que mostra esse ambiente da aula de forma improvisada, mas, infelizmente, na maioria das escolas ribeirinhas esse processo acontece dessa forma.

Fizeram-se algumas indagações da seguinte forma: Qual a sua opinião a respeito da interação dos alunos com AH/S com os demais alunos, em relação a seu desenvolvimento? Os participantes responderam da seguinte forma: 
Meus coleguinhas são legais, todos estudam, mas é muito ruim a casa da escola, a professora arruma a sala por causa de outros alunos maiores na sala; o recreio é muito bom todos conversam (Aluno Pedro).

Logo, os professores da sala de aula comum e do AEE, o coordenador pedagógico da escola e principalmente o aluno Pedro, que diz "Meus coleguinhas são legais", enfatizam a necessidade da interação do aluno com $\mathrm{AH} / \mathrm{S}$ com os demais alunos para que ocorra o desenvolvimento de todos, mas dentro desse contexto, esses profissionais necessitam de conhecimentos que os habilitem a reconhecer, desafiar e apoiar esses alunos, a fim de que possam desenvolver satisfatoriamente suas potencialidades.

\section{Conclusões}

A análise de dados da investigação como um todo, por meio de teorizações progressivas, aponta que existem inúmeras discrepâncias entre o que se estabelece em termos legais mediante a política educacional da Educação Especial na perspectiva inclusiva (BRASIL, 2008) e a realidade escolar da escola ribeirinha estudada. Se, por um lado, no contexto investigado são cumpridos alguns aspectos formais da legislação, por outro, ficam questionamentos quanto ao fato da escola pesquisada estar contribuindo efetivamente para o pleno desenvolvimento do aluno com AH/S e atuando como suporte ao ensino inclusivo.

Os resultados referentes à análise da realidade investigada mostram que essas discrepâncias são impeditivas para que a escola em questão cumpra formalmente os requisitos legais estabelecidos para a construção de uma educação inclusiva, então elencamos alguns elementos tais como a inexistência do papel/função da sala de AEE ou de recursos multifuncionais, não ocorrendo verdadeiramente o trabalho de Atendimento Educacional Especializado, não desenvolvido em virtude de diversos fatores, como falta de estrutura física, administrativa, recursos humanos e pedagógicos que não são viabilizados pela Secretaria de Educação para a escola em questão.

Cabe mencionar também o fato de não existir o professor especializado, que tenha a formação apropriada para realização do atendimento educacional especializado, sendo que a referida escola apresenta apenas um (01) aluno com AH/S. Os dados mostram que a sala improvisada do AEE se apresenta fora de condições e dos padrões para realização do trabalho pedagógico com alunos com $\mathrm{AH} / \mathrm{S}$.

$\mathrm{O}$ aluno Pedro com AH/S, foco da pesquisa, estava matriculado regularmente no $3^{\circ}$ ano do ensino fundamental I, frequentando a sala de aula multisseriada, mas não ocorrem verdadeiras implementações e ações educacionais inclusivas, nem qualquer trabalho que o 
reconheça em suas reais potencialidades por falta de capacitação dos profissionais da escola que não têm a devida formação para o trabalho com $\mathrm{AH} / \mathrm{S}$, impossibilitando as práticas inclusivas e dificultando o trabalho pedagógico, impossibilitando assim o desenvolvimento de ferramentas de adaptações curriculares individuais para o AEE, fazendo com que essas dificuldades provoquem a falta de acompanhamento pedagógico especifico para o aluno com $\mathrm{AH} / \mathrm{S}$.

Dessa forma, a partir dos resultados obtidos na entrevista e das observações da pesquisa, pode-se dizer que existe a necessidade urgente de refletir sobre os fundamentos teóricos e práticos adotados em salas de aula multisseriadas da escola, sobre o enfoque de alunos com AH/S. Valendo dizer que a escola investigada e os profissionais não estão em consonância com os processos de ensino e de aprendizagem para o aluno que apresenta características de AH/S.

\section{REFERÊNCIAS}

ALVES-MAZZOTTI, A. J; GEWANDSZNAJDE, F. O método nas ciências naturais e sociais: pesquisa quantitativa e qualitativa. 2. ed. São Paulo: Pioneira, 2002. 198p.

ALMEIDA, E. M. M. Educação Ribeirinha na Amazônia. São Leopoldo: Oikos, 2010.

ALMEIDA, E. M. M. Ecologia de Saberes: Um estudo do diálogo entre o conhecimento escolar e o saber popular dos ribeirinhos da Ilha do Açaí. Orientador: Ana Maria Haddad Baptista. 2016. 227 f. Tese (Doutorado em Educação) - Departamento de pós-graduação em Educação da Universidade Nove de Julho - UNINOVE, São Paulo, 2016. Disponível em: http://bibliotecatede.uninove.br/handle/tede/1560. Acesso em: 10 mar. 2020.

ANDRÉ, M. E. D. A. Etnografia da Prática Escolar. 9. ed. São Paulo: Papirus, 2003.

BEZERRA NETO, L. Na luta pela terra, a conquista do conhecimento. São Carlos: Pedro \& João Editores, 2013.

BOGDAN, R.; BIKLEN, S. Investigação qualitativa em educação. 3. ed. Porto: Porto Editora, 1994.

BRASIL. Constituição Federal de 1988. Brasília, 1988. Disponível em: http://www.planalto.gov.br/ccivil_03/Constituicao/Constituicao.htm. Acesso: 19 de fev. 2014.

BRASIL. Lei n. 9394, de 20 de dezembro de 1996. Brasília. Dário Oficial da União, Brasília, DF, 23 dez. 1996. Disponível em:

http://www.planalto.gov.br/ccivil_03/LEIS/L9394.htm. Acesso em 06 de out. de 2014.

BRASIL. Ministério da educação: Diretrizes nacionais para a Educação Especial na Educação Básica. Secretaria de Educação Especial. MEC. SEESP, 2001. 
BRASIL. Lei n. 10172, de 09 de janeiro de 2001. Aprova o Plano Nacional de Educação e dá outras providências. Dário Oficial da União, Brasília, DF, 10 jan. 2001. Disponível em: http://www.planalto.gov.br/ccivil_03/leis/leis_2001/110172.htm. Acesso em 05/01/2007.

BRASIL. Resolução n. 2, de 11 de fevereiro de 2001. CNE/CEB. Institui Diretrizes Nacionais para a Educação Especial na Educação Básica. Brasília, DF: MEC/SEESP, 2001. Disponível em: portal.mec.gov.br/seesp/arquivos/pdf. Acesso em: 14/12/2011.

BRASIL. Secretaria de Educação Especial. Subsídios para a organização e funcionamento de serviços de educação especial: Área de Altas Habilidades. Brasília: MEC/SEESP, 2006.

BRASIL. Comitê Nacional de Educação em Direitos Humanos. Plano Nacional de Educação em Direitos Humanos. Brasília: Secretaria Especial dos Direitos Humanos, Ministério da Educação, Ministério da Justiça, UNESCO, 2006.

BRASIL. Ministério da Educação. Política Nacional de Educação Especial na Perspectiva da Educação Inclusiva. Brasília: MEC, 2008. Disponível em:

http://portal.mec.gov.br/seesp/arquivos/pdf/politica.pdf. Acesso em: 12 mar. 2015.

BRASIL. Lei n. 12.796, de 4 de abril de 2013. Altera a Lei no 9.394, de 20 de dezembro de 1996, que estabelece as diretrizes e bases da educação nacional, para dispor sobre a formação dos profissionais da educação e dar outras providências. Dário Oficial da União, Brasília, DF, 5 abr. 2013a. Disponível em: http://www.planalto.gov.br/ccivil_03/_Ato20112014/2013/Lei/L12796.htm. Acesso em: 12 mar. 2015.

CALDART, R, S. Por Uma Educação do Campo: traços de uma identidade em construção. In: KOLLING, E. J.; CERIOLI, P. R.; CALDART, R. S. (Org.). Educação do Campo: identidade e políticas públicas. Brasília: Articulação Nacional por uma Educação do Campo, p. $12-60,2010$.

CARVALHO, M. C. B. O lugar da família na política social. In: M. C. B. Carvalho (Org.). A família contemporânea em debate. São Paulo: EDUC. 3. ed. p. 13-21, 2006.

CHICON, J. F. Práticas Pedagógicas para o Ensino de Crianças Especiais, 2 ed. Rio de Janeiro: Cortez, 1999.

DELOU, C. M. C. Educação do Aluno com Altas habilidades/superdotação: Legislação e Políticas Educacionais para a Inclusão. In: FLEITH, D. S. (org). A construção de práticas educacionais para alunos com altas habilidades/superdotação. Volume 1: orientação a professores/organização. Brasília: Ministério da Educação, Secretaria de Educação Especial, 2007.

DELOU, C. M. C. A formação de professores para estudantes com altas habilidades/ superdotação no Brasil. In: MENDES, E. G., ALMEIDA, M. A. (Orgs.). Dimensões Pedagógicas nas práticas de inclusão escolar. Marília: ABPEE, v. 2, p. 333-345, 2012.

ESTATUTO DO SINDICATO DOS TRABALHADORES DE EDUCAÇÃO MAZAGÃO DO AMAPÁ. Manual de registro fotográfico. 2016. Disponível em: http://www.sintemap.org.br/v2.0/. Acesso em: 30 mar. 2016. 
FREITAS, S. N.; PÉREZ, S. G. P. B. Altas habilidades/superdotação: atendimento especializado. Marília, SP: ABPEE, 2012.

HAGE, S. M. Classes multisseriadas: desafios da educação rural na Amazônia. Belém, Pará, 2004. Disponível em: http://www.educampoparaense.org. Acesso em: 28 jan. 2013.

HAGE, S. M. Classes multisseriadas: desafios da educação rural no estado do Pará/região Amazônica. In: HAGE, S. M. (Org.). Educação do campo na Amazônia: retratos de realidade das escolas multisseriadas no Pará. Belém: Gutemberg, 2005.

\section{INSTITUTO BRASILEIRO DE GEOGRAFIA E ESTATÍSTICA. IBGE. Censo} demográfico 2013. 2013. Disponível em:

http://www.ibge.gov.br.portal.mec.gov.br/escolasdocamporibeirinhasbuscageral/212noticias//home/. Acesso em: 30 de fev. 2016.

\section{INSTITUTO BRASILEIRO DE GEOGRAFIA E ESTATÍSTICA. IBGE. Censo}

demográfico 2014. Índice de analfabetismo da população no Município de Mazagão. Disponível em: http://www.ibge.gov.br.portal.mec.gov.br/busca-geral/212-noticias//home/ Acesso em: 19 de mar. 2016.

\section{INSTITUTO BRASILEIRO DE GEOGRAFIA E ESTATÍSTI. IBGE. Censo demográfico} 2016. Pesquisa Nacional por Amostra de Domicílios, a taxa de analfabetismo entre brasileiros com 15 anos ou mais e as características gerais da população de Mazagão. Rio de Janeiro: IBGE, 2016. Disponível em: http://censo2016.ibge.gov.br/resultados. Acesso em: 06 mar. 2017.

INSTITUTO BRASILEIRO DE GEOGRAFIA E ESTATÍSTI. IBGE. Censo demográfico 2016. A proporção de pessoas ocupadas em relação à população total era de $4.4 \%$ na comparação com os outros municípios do estado. Rio de Janeiro: IBGE, 2016. Disponível em http://www.ibge.populaçãototalmunicipios.gov.br/home/. Acesso em: 19 de fevereiro. 2017.

\section{INSTITUTO BRASILEIRO DE GEOGRAFIA E ESTATÍSTI. IBGE. Censo demográfico} 2017. Concentração da população, estimada em 20.387 habitantes e área de $13.294,778$ km². 2017. Disponível em: http://www.ibge.gov.br/concentracaoda.populacaohome/. Acesso em: 23 de maio. 2017.

\section{INSTITUTO NACIONAL DE ESTUDOS E PESQUISAS EDUCACIONAIS ANÍSIO} TEIXEIRA - INEP. Censo Escolar 2015. Disponível em:

http://www.inep.gov.br/basica/censo/escolar/resultados.htm. Acesso: 19 de fev. 2015.

\section{INSTITUTO NACIONAL DE ESTUDOS E PESQUISAS EDUCACIONAIS ANÍSIO} TEIXEIRA - INEP. Censo Escolar 2016. Disponível em:

http://www.inep.gov.br/basica/censo/escolar/educacaoespecialresultados.htm. Acesso em: 20 de fev. 2017.

LAVILLE, C; DIONE, J. A construção do saber: manual de metodologia da pesquisa em ciências humanas. Porto Alegre: Artmed, 2000.

LUDKE, M.; ANDRÉ, M. E. D. A. Pesquisa em educação: abordagens qualitativas. São Paulo: EPU, 1986. 99p. 
MAZAGÃO. Indicação n. 01/03 de 02 de fevereiro de 2017. Elabora dados de matrícula complementares para a Secretaria de Estado da Educação/Prefeitura Municipal de Mazagão: SEED/PMMz, 2017.

MOLINA, M. C; FREITAS, H. C. de A. Educação do campo. Brasília. Em Aberto, v. 24, n. 85, p. 11, abr. 2011.

MOREIRA, A. F.; CANDAU, V. M. Currículo, conhecimento e cultura. Brasília: Ministério da Educação, Secretaria de Educação Básica, 2008.

MOURA, T. V.; SANTOS, F. J. S. Por uma pedagogia das classes multisseriadas. In: EPENNEncontro de Pesquisa Educacional do Norte e Nordeste, 20. 2011, Manaus-AM. Anais do XX EPENN. Manaus-AM, UFAM, 2011. (GT 26 - Educação e Ruralidades).

ORGANIZAÇÃO DAS NAÇÕES UNIDAS - ONU. Declaração Universal dos Direitos Humanos. 1948. Disponível em: http://www.onubrasil.org.br/documentos_direitoshumanos.php. Acesso em 19 de agosto de 2015.

\section{ORGANIZAÇÃO DAS NAÇÕES UNIDAS - ONU. Fórum Mundial de Educação na}

Coréia do Sul. 2015. Disponível em. http://www.onubrasil.org.br/documentos_declaracaoincheon.php. Acesso em 19 de agosto de 2015.

PÉREZ, S. G. P. B. Mitos e Crenças sobre as Pessoas com Altas Habilidades: alguns aspectos que dificultam o seu atendimento. Cadernos de Educação Especial. Santa Maria, n. 22, p. 45-59, 2003.

PÉREZ, S. G. P. B. Gasparzinho vai à escola: um estudo sobre as características do aluno com altas habilidades produtivo criativo. Orientador: Claus Dieter Stobäus. 2004. 306 f. Dissertação (Mestrado) - Programa de Pós-Graduação em Educação - Pontifícia Universidade Católica do Rio Grande do Sul, Porto Alegre, 2004. Disponível em: http://www.bdae.org.br:8080/jspui/bitstream/123456789/898/1/tese.pdf. 10 mar. 2020.

PÉREZ, S. G. P. B. Políticas públicas para as altas habilidades/superdotação: Incluir ainda é preciso. In: MENDES, E. G., ALMEIDA, M. A. (Orgs.). Dimensões Pedagógicas nas práticas de inclusão escolar. Marília: ABPEE, v. 2, p. 347-362, 2012.

PLETSCH, M. D; FONTES, R. de S. A inclusão escolar de alunos com necessidades especiais: diretrizes, práticas e resultados de uma experiência brasileira. Revista Educar, Jalisco, México, n. 37, p. 87-97, 2006.

RIBEIRO, D. O povo brasileiro: a formação e o sentido do Brasil. $6^{\mathrm{a}}$ reimpressão. São Paulo: Companhia das Letras, 2006.

RODRIGUES, D. S. S. et al. Cultura, cultura popular amazônica e a construção imaginária da realidade. In: OLIVEIRA, Ivanilde Apoluceno de (Org.). Cartografias de saberes:

representações sobre a cultura amazônica em práticas de educação popular. Belém: EDUEPA, 2004. 
SASSAKI, R. K. Inclusão. Construindo uma sociedade para todos. Rio de Janeiro: WVA, 1997.

SILVA, M. das G. S. N. O espaço ribeirinho. São Paulo: Terceira Margem, 2000.

TRIVIÑOS, A. N. S. Introdução à pesquisa em ciências sociais: a pesquisa qualitativa em educação. São Paulo: Atlas, 1987.

UNESCO. Declaração Mundial sobre Educação para Todos: plano de ação para satisfazer as necessidades básicas de aprendizagem. UNESCO, Jomtiem/Tailândia, 1990.

UNESCO. Declaração de Salamanca e linha de ação sobre necessidades educativas especiais. Brasília: UNESCO, 1994.

WERNECK, C. Ninguém mais vai ser bonzinho na sociedade inclusiva, 2. ed. Rio de Janeiro: WVA, 2000.

WINNER, E. Crianças superdotadas: mitos e realidades. Tradução Sandra Costa. Porto Alegre: Artes Médicas, 1998.

WOLFF, F. Por trás do espetáculo: o poder das imagens. In: NOVAES, A. (org). Muito além do espetáculo. São Paulo: Editora Senac São Paulo, p. 16-45, 2005.

\section{Como referenciar este artigo}

FERREIRA, José Adnilton Oliveira; CARNEIRO, Relma Urel Carbone. O aluno com altas habilidades/superdotação em escola ribeirinha na Amazônia. Revista on line de Política e Gestão Educacional, Araraquara, v. 24, n. 1, p. 247-269, jan./abr., 2020. e-ISSN:1519-9029. DOI: https://doi.org/10.22633/rpge.v24i1.13421

Submetido em: 14/04/2019

Revisões requeridas: $20 / 08 / 2019$

Aprovado em: 30/11/2019

Publicado em: 06/001/2020 